\title{
Laparoscopic Cholecystectomy Is a Safe Procedure for the Treatment of Porcelain Gallbladder
}

Porcelain gallbladder is a rare condition, characterized by a calcified gallbladder wall (1). We recently treated three patients with the condition. Although a porcelain gallbladder is generally difficult to grasp with forceps, two of these patients were successfully treated by laparoscopic cholecystectomy. The other patient had to undergo conversion to an open cholecystectomy, due to the presence of a firm intraperitoneal fibrous adhesion.

With the advances made in recent years (2), both in equipment and in newly developed techniques, laparoscopic management of cholecystolithiasis and choledocholithiasis has now become an increasingly safe technique. It is no exaggeration to say that there are no longer any contraindications to laparoscopic techniques, except in very rare conditions. Neil et al. (3) were the first to report that porcelain gallbladder was a relative contraindication to laparoscopic cholecystectomy. Although our two cases were successfully managed laparoscopically, some technical difficulties in carrying out cholecystectomy do still remain. The wall of the gallbladder is sometimes too hard to grasp with forceps after it is peeled off, making dissection difficult.

There are three important factors for safe laparoscopic cholecystectomy in the treatment of porcelain gallbladder. First, it is absolutely essential that preoperative DIC (drip infusion cholangiography) or endoscopic retrograde cholangiopancreatography (4) should be carried out in order to provide an accurate assessment of the length of the cystic duct. More than $90 \%$ of porcelain gallbladder cases are complicated by an obstruction of the cystic duct, which is therefore usually very short, and adheres to the surrounding tissues (Figure 1). If the cystic duct is long enough to grasp, then the surgeon can securely grasp the neck portion during the operation. If the cystic duct is not long enough to grasp or for intraoperative cholangiography to be carried out, then the surgeon should consider changing the method either to cholangiography or to an open cholecystectomy (Figure 2). Secondly, intraoperative cholangiography can be helpful in delineating the biliary anatomy, in order to avoid iatrogenic injury (5). Thirdly, when the exposure of the cystic duct is difficult and hazardous, an anterograde or laparoscopic cholecystectomy is recommended after temporary clipping of the cystic duct and artery. This procedure provides better definition of both the cystic duct and the common bile duct. In addition, there is also less chance of injury to the bile duct. Laparoscopic removal of the gallbladder in the treatment of porcelain gallbladder should only be carried out with extreme care, and following the procedures described above.

T. Tomioka, Y. Tajima, K. Inoue, S. Onizuka, Y. Ikematsu, T. Kanematsu

Second Dept. of Surgery, Nagasaki University School of Medicine, Nagasaki, Japan

\section{References}

1. Shimizu M, Miura J, Tanaka T, et al. Porcelain gallbladder; relation between its type by ultrasound and incidence of cancer. J Clin Gastroenterol 1989; 11:471-6.

2. Tomioka T, Ikematsu Y, Tajima Y, et al. Tap needle for laparoscopic surgery: a safe and easy technique for holding tissues. Surg Laparosc Endosc 1994; 4: 361-3.

3. Neil T, Welch R, Robert JF, Ronald AH. Beware of the porcelain gallbladder during laparoscopic cholecystectomy. Surg Laparosc Endosc 1991; 1: 202-5.

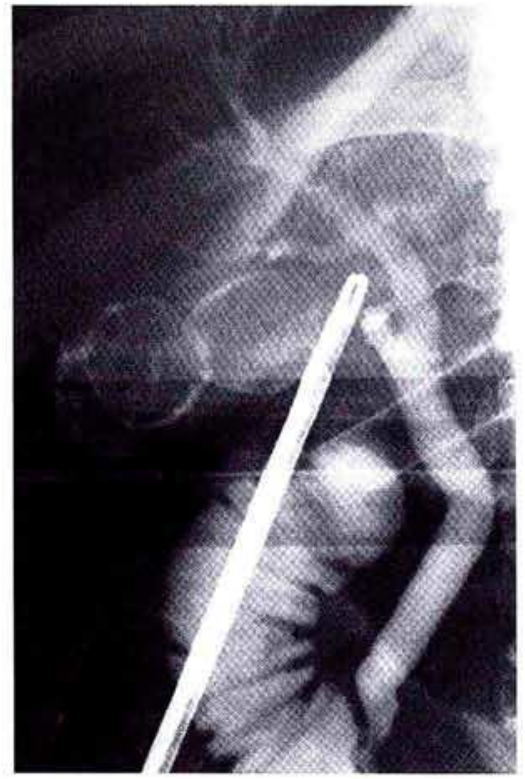

Figure 1: intraoperative cholangiography, showing the remnant of the cystic duct, a faint common bile duct, and a snow man-shaped calcified gallbladder. The remnant of the cystic duct was found to be short, but long enough for end clips to be used.

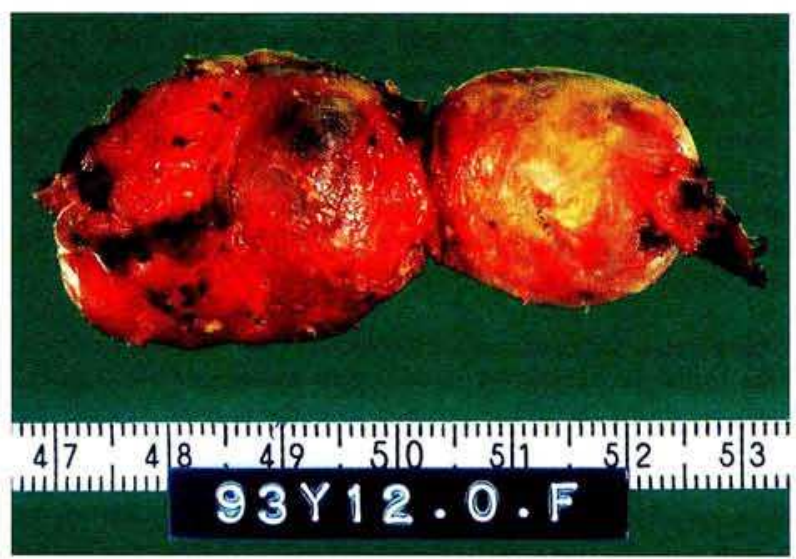

Figure 2: The resected gallbladder, showing the stony, hard wall and the soft, pig tail-like cystic duct. The serosa has all been peeled off.

4. Neuhaus H, Feussner H, Ungeheuer R, et al. Prospective evaluation of the use of endoscopic retrograde cholangiography prior to laparoscopic cholecystectomy. Endoscopy 1992; 24: $745-9$.

5. Rosenthal RJ, Steigerwald SD, Imig R, et al. Role of intraoperative cholangiography during endoscopic cholecystectomy. Surg Laparosc Endosc 1994; 4: 171-4.

Corresponding Author

T. Tomioka, M.D.

Second Dept. of Surgery

Nagasaki University School of Medicine

1-7-1 Sakamoto

Nagasaki City 852 , Japan

Fax: +81-958-49-7319 